\title{
Simulation Study of a Membrane Reactor for Ultrapure Hydrogen Recovery from Methanol Steam Reforming Reaction under Periodic Steady-State
}

\author{
Lemnouer Chibane \\ Laboratoire de Génie des Procédés Chimiques (LGPC), Département de Génie des Procédés, \\ Faculté de Technologie, Université Ferhat Abbas, Sétif 1, Algérie
}

Received: $15^{\text {th }}$ July 2017; Revised: $26^{\text {th }}$ November 2017; Accepted: $8^{\text {th }}$ December 2017; Available online: $11^{\text {st }}$ June 2018; Published regularly: $1^{\text {st }}$ August 2018

\begin{abstract}
Steam reforming of methanol over $\mathrm{Cu} / \mathrm{ZnO} / \mathrm{Al}_{2} \mathrm{O}_{3}$ catalyst was theoretically studied under created unsteady state. A mathematical approach was proposed to evaluate the effect of periodic inputs on reactor performance. The efficacy of the periodic separating reactor in term of pure hydrogen and of methanol conversion was measured during the reaction of methanol steam reforming. The obtained results showed that under certain operating conditions the periodic operation can be used advantageously to increase the reactor ability up to a level higher than the maximal steady-state. Moreover, our findings showed that the pumping of hydrogen through the membrane was stimulated by the effect of periodic operations. The predicted results suggested that the created unsteady state mode by using a square wave function could give the better performances compared to the sinusoidal mode. Copyright (c) 2018 BCREC Group. All rights reserved
\end{abstract}

Keywords: hydrogen production; methanol conversion; membrane reactor; periodic operation; unsteady state

How to Cite: Chibane, L. (2018). Simulation Study of a Membrane Reactor for Ultrapure Hydrogen Recovery from Methanol Steam Reforming Reaction under Periodic Steady-State. Bulletin of Chemical Reaction Engineering \& Catalysis, 13 (2): 275-285 (doi:10.9767/bcrec.13.2.1340.275-285)

Permalink/DOI: https://doi.org/10.9767/bcrec.13.2.1340.275-285

\section{Introduction}

Currently, environmental pollution became one of the most focused research area that receives a special attention. Emission from internal combustion engines and electric power generation plants are the largest sources of air pollution [1]. Therefore, several researches are aimed to find an alternative power sources for vehicles [2,3]. Moreover, the global demand and

* Corresponding Author.

E-mail: lchibane@yahoo.com (L. Chibane)

Tel: +213 559736695; Fax: +213 36925133 the great need in term of energy have motivated research and development in fuel cell domain [4]. Hydrogen fuel cell seems to be a promising solution to these global environmental and energy problems by acting on the use of hydrogen in fuel cells produces useful energy [5,6]. Hydrogen is a promising alternative energy source that can be used in fuel cell applications to produce electrical energy. Among the various fuels which can be renewed to hydrogen, alcohols, in particular methanol is attractive for fuel-cell engines in transportation applications. Because of its safe manipulation and of its ease production from a variety of feedstock, such as: renewable 
sources $[5,7,8]$, methanol is very hopeful as a source of raw material for hydrogen production. It is also easily transformed in the presence of water to generate a hydrogen-rich mixture suitable for feeding fuel cells [9] and it could be activated at low temperatures $\left(200-300^{\circ} \mathrm{C}\right)$ than other hydrocarbons [10,11]. So, it is considered as a source for fuel cell powered vehicles $[12,13]$. Steam reforming of methanol is considered to be the most effective route for hydrogen production and has been the subject of several researches works [14-16].

When this reaction was carried out in a traditional reactor leads to a hydrogen-containing mixture, so hydrogen needs purification before it can be used. It is known that the fuel cells need a high degree of hydrogen purity [17]. Thus, purification steps are required. The concept of membrane reactor can be an economical and effective way for this purpose [18]. So, it can be used to further increase the hydrogen production and the reformer efficiency. Thus, the intensification of technologies is designed to improve the process by acting on operated parameters. Running chemical reactors in unsteady state is one of the possible used technologies, especially the change of the reactant composition [19]. For a given process, some inputs are either fixed constants or can be controlled. If the variables are controlled, the state variables are periodic functions of time and the process operated in a periodic state [20]. Our attention is focused on enhancing the performance of a $\mathrm{Pd}$-membrane reactor used for pure hydrogen production from the reaction of methanol steam reforming. The novelty of this work is to prove the possibility of intensifying the process by simultaneous application of a sequence of steady state in reaction and permeate zones which constitute the reactor under study. A comparative simulation study of the dynamics and efficiency of methanol steam reforming have been done by using the concept of periodic reactor-separating via a sinusoidal and a square functions.

\section{Mathematical Model}

\subsection{Reactor description}

A combination of reaction and separation in a single unit has been explored for pure hydrogen production during the reaction of methanol steam reforming. Figure 1 shows a scheme of the Pd-membrane reactor under study. Under created unsteady state, the square and sinusoidal function is one of the perturbation functions used in the periodic operations. For each function, the cycle is described by the period $\tau=2 \pi$, the amplitude $\sigma$ and the angular frequency $\omega$. These functions are defined as follows:

$$
\begin{gathered}
f_{1}(t)=\sin (\omega t) \\
f_{2}(t)=\left\{\begin{array}{l}
+1 \text { for } 0 \leq t \leq \tau / 2 \\
-1 \text { for } \tau / 2 \prec t \prec \tau
\end{array}\right.
\end{gathered}
$$

In order to represent the steady state and the unsteady state of the membrane reactor, a mathematical model is adopted subject to the following assumptions: the membrane reactor is operated under isothermal and isobaric conditions; the thermal effect is not taken in account; plug-flow is assumed for the reaction and permeate sides; ideal gas law is applicable; the catalyst deactivation by coke formation is not considered; the periodic operation is only imposed for the steam to methanol ratio and sweeping gas to methanol ratio via a square and a sinus way; under forcing conditions, it is supposed that the period of change of the modulation function is significantly larger, so the reactor operates under quasi steady state conditions; the membrane is only permeable to hydrogen and possesses an infinite selectivity. From these assumptions, the governing equations for the reaction and permeate sides are given below.

\subsection{Chemical reaction scheme, kinetics and mass balance}

The reaction network used for modeling the process of methanol steam reforming consists of three following reactions, respectively [2124 ], i.e. methanol steam reforming $(R)$, watergas-shift $(W)$, and decomposition $(D)$ reactions:

$$
\mathrm{CH}_{3} \mathrm{OH}+\mathrm{H}_{2} \mathrm{O} \Leftrightarrow 3 \mathrm{H}_{2}+\mathrm{CO}_{2} \Delta \mathrm{H}_{298}=49 \mathrm{~kJ} / \mathrm{mol}
$$

$$
\mathrm{CO}+\mathrm{H}_{2} \mathrm{O} \Leftrightarrow \mathrm{H}_{2}+\mathrm{CO}_{2} \quad \Delta \mathrm{H}_{298}=-41 \mathrm{~kJ} / \mathrm{mol}
$$

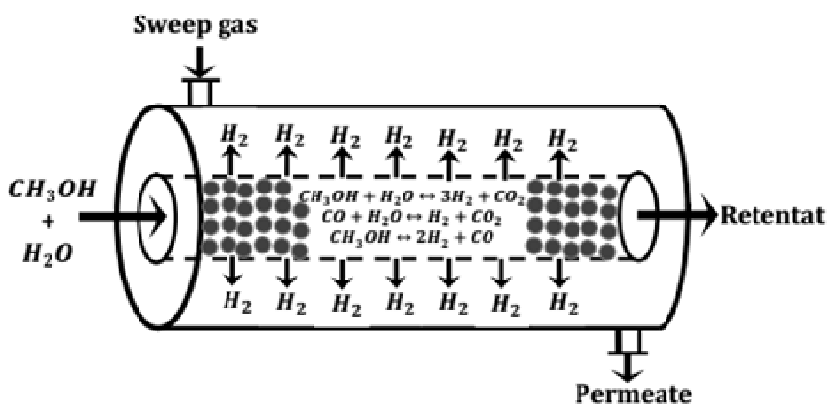

Figure 1. Schematic diagram of the membrane reactor 
$\mathrm{CH}_{3} \mathrm{OH} \Leftrightarrow 2 \mathrm{H}_{2}+\mathrm{CO} \quad \Delta \mathrm{H}_{298}=90 \mathrm{~kJ} / \mathrm{mol}$

Reactions (3) and (5) are both reversible and endothermic reactions and proceed under volume increase, suggesting that the highest methanol conversions are obtained at high temperature and low pressure. The exothermic reaction (4) is the so-called water gas-shift reaction which proceeds simultaneously with methanol steam reforming. This process is strongly endothermic and its reaction temperature is in the range of $160-260{ }^{\circ} \mathrm{C}[25]$. The reaction conditions of methanol steam reforming are relatively mild, with typical temperatures around $300{ }^{\circ} \mathrm{C}$ [26] and over $\mathrm{Cu} / \mathrm{ZnO}$ based catalysts [15]. The kinetic model developed by Peppley on $\mathrm{Cu} / \mathrm{ZnO} / \mathrm{Al}_{2} \mathrm{O}_{3}$ catalyst is used for simulation due to its predictive capability over a wide range of temperature and pressure [26]. The $\mathrm{Cu} / \mathrm{ZnO}$ is a highly selective catalyst, giving a rather high $\mathrm{CO}_{2} / \mathrm{CO}$ ratio, making it an attractive candidate for the fuel processing. Furthermore, the catalyst has a reasonable activity at moderate temperatures $\left(200-250{ }^{\circ} \mathrm{C}\right)$. On the other hand, the catalyst has the disadvantage of sensitivity to high operating temperatures (above $270-280{ }^{\circ} \mathrm{C}$ ) [12]. The Peppley reaction network is based on the reformingdecomposition-water-gas shift (WGS) mechanism and it consists of rate expressions in Langmuir-Hinshelwood form [22] (Equations (6-8)).

For $j=R, W$, and $D, k_{j}$ is the reaction rate constant of reaction $j$ which is defined by Arrhenius equation (Equation (9), and $K_{j}$ is the equilibrium constant, which is defined by Van't Hoff equation (Equation (10)).

$$
\begin{gathered}
k_{j}=k_{0, j} \exp \left(-E_{j} / R T\right) \\
K_{j}=K_{0, j} \exp \left(-\Delta H_{j} / R T\right)
\end{gathered}
$$

$K_{i}^{*}\left(I=\mathrm{CH}_{3} \mathrm{O}_{(1)}, \mathrm{CH}_{3} \mathrm{O}_{(2)}, \mathrm{OH}_{(1)}, \mathrm{OH}_{(2)}, \mathrm{H}_{2(1 \mathrm{a})}\right.$, and $\left.\mathrm{H}_{2(2 \mathrm{a})}\right)$ is the species adsorption constant defined in Equation (11).

$$
K_{i}^{*}=\exp \left(\frac{\Delta S_{i}^{*}}{R}-\frac{\Delta H_{i}^{*}}{R T}\right)
$$

$P_{M}, P_{H 2}, P_{C O 2}, P_{W}$, and $P_{C O}$ are the partial pressures of $\mathrm{CH}_{3} \mathrm{OH}, \mathrm{H}_{2}, \mathrm{CO}_{2}$, and $\mathrm{CO}$, respectively. Meanwhile, $C^{T}{ }_{S 1}$ and $C^{T}{ }_{S 1 a}$ are the surface concentration of site types 1 or $1 \mathrm{a}$ $\left(\mathrm{mol} / \mathrm{m}^{2}\right), C_{S 2}^{T}$ and $C^{T}{ }_{S 2 \alpha}$ are the surface concentration of site types 2 or $2 \mathrm{a}\left(\mathrm{mol} / \mathrm{m}^{2}\right)$, and $S_{C}$ is the surface area for methanol reforming catalyst $\left(\mathrm{m}^{2} / \mathrm{kg}\right)$.

The $\mathrm{Cu} / \mathrm{ZnO} / \mathrm{Al}_{2} \mathrm{O}_{3}$ catalyst properties and reactor dimensions, operating conditions, kinetic and thermodynamic parameters used for simulation are summarized in Tables 1 and 2 . Since only two of these reactions are linearly independent, reaction (3) is the sum of the other two reactions. the problem is described by mean of conversion of methanol $\left(\mathrm{X}_{\mathrm{CH} 3 \mathrm{OH}}\right)$ and of carbon dioxide $\left(X_{\mathrm{CO} 2}\right)$. Under steady state conditions, the molar flow rates for each species are expressed in Equations (12-16).

a) In reaction side:

$$
\begin{aligned}
& \widetilde{F}_{\mathrm{CH}_{3} \mathrm{OH}}=F_{\mathrm{CH}_{3} \mathrm{OH}}^{0}\left(1-X_{\mathrm{CH}_{3} \mathrm{OH}}\right) \\
& \widetilde{F}_{\mathrm{H}_{2} \mathrm{O}}=F_{\mathrm{H}_{2} \mathrm{O}}^{0}-F_{\mathrm{CH}_{3} \mathrm{OH}}^{0} X_{\mathrm{CO}_{2}} \\
& \widetilde{F}_{\mathrm{CO}_{2}}=F_{\mathrm{CO}_{2}}^{0}+F_{\mathrm{CH}_{3} \mathrm{OH}}^{0} X_{\mathrm{CO}_{2}} \\
& \widetilde{F}_{\mathrm{CO}}=F_{\mathrm{CO}}^{0}-F_{\mathrm{CH}_{3} \mathrm{OH}}^{0} X_{\mathrm{CO}_{2}}+F_{\mathrm{CH}_{3} \mathrm{OH}}^{0} X_{\mathrm{CH}_{3} \mathrm{OH}} \\
& \widetilde{F}_{\mathrm{H}_{2}}=F_{\mathrm{H}_{2}}^{0}+2 F_{\mathrm{CH}_{3} \mathrm{OH}}^{0} X_{\mathrm{CH}_{3} \mathrm{OH}}+F_{\mathrm{CH}_{3} \mathrm{OH}}^{0} X_{\mathrm{CO}_{2}}-F_{\mathrm{H}_{2}}^{P}
\end{aligned}
$$

The hydrogen flow rate in permeate side $\left(F_{H 2, p}\right)$ $(\mathrm{mol} / \mathrm{s})$ is given by the following Equations (17, 18) as function on the hydrogen recovery $Y_{H_{2}}$ ):

$$
\begin{aligned}
& \widetilde{F}_{\mathrm{H}_{2}}^{P}=Y_{\mathrm{H}_{2}} F_{\mathrm{CH}_{3} \mathrm{OH}}^{0} \\
& \widetilde{F}_{T}=F_{T}^{0}+F_{\mathrm{CH}_{3} \mathrm{OH}}^{0}\left(2 X_{\mathrm{CH}_{3} \mathrm{OH}}-Y_{\mathrm{H}_{2}}\right)
\end{aligned}
$$


The initial total molar flow is given as:

$$
F_{T}^{0}=\sum_{i=1}^{5} F_{i}^{0}
$$

Because of kinetic limitations, zero cannot be used as a value for hydrogen partial pressure because it will give us infinite kinetics. To overcome this problem, a small quantity of hydrogen has to be used $\left(F_{H 2}^{v}=10^{-10} \mathrm{~mol} / \mathrm{s}\right)$. In absence of $\mathrm{CO}_{2}$ and $\mathrm{CO}$ in the reactor inlet, the initial total molar flow rate is:

$$
F_{\mathrm{T}}^{0}=F_{\mathrm{CH}_{3} \mathrm{OH}}^{0}+F_{\mathrm{H}_{2} \mathrm{O}}^{0}+F_{\mathrm{H}_{2}}^{0}
$$

The total molar flow can be expressed as:

$$
\widetilde{F}_{T}=F_{\text {СңОH }}^{0}\left(1+\left(\frac{S}{C}\right)+2 X_{\mathrm{CңOH}}-Y_{\mathrm{H}_{2}}+\frac{F_{\mathrm{H}_{2}}^{0}}{F_{\mathrm{CH} O \mathrm{H}}^{0}}\right)
$$

Under the periodic operations, the steam to methanol ratio $(S / C)$ can be written at constant inlet feed of methanol as:

$$
\left(\frac{S}{C}\right)(t)=\frac{F_{\mathrm{H}_{2} \mathrm{O}}(t)}{\widetilde{F}_{\mathrm{CH}_{3} \mathrm{OH}}}
$$

Using a periodic function $f(t)$, it is assumed that the steam molar flow $\left(\mathrm{H}_{2} \mathrm{O}\right)$ equals to the sum of the steady state value and a time $(t:(\mathrm{s}))$ dependent value:

$$
F_{\mathrm{H}_{2} \mathrm{O}}(t)=\widetilde{F}_{\mathrm{H}_{2} \mathrm{O}}+\widetilde{F}_{\mathrm{H}_{2} \mathrm{O}} \sigma_{1} f(t)
$$

Table 1. Reactor dimensions and operating conditions

\begin{tabular}{lc}
\hline \multicolumn{1}{c}{ Parameters } & Value \\
\hline Reaction temperature $(T, \mathrm{~K})$ & 533 \\
Reaction pressure side $(P r, \mathrm{bar})$ & 1.4 \\
Permeation pressure side $\left(P_{P}, \mathrm{bar}\right)$ & 1.013 \\
Methanol inlet flow rate $\left(F^{b}{ }_{C H 3 H}, \mathrm{~mol} / \mathrm{s}\right)$ & $95 \times 10^{-3}$ \\
Steam to methanol ratio $(S / C)$ & 1 \\
Sweeping gas to methanol ratio $(I)$ & 3 \\
Catalyst properties and reactor dimensions & \\
Catalyst weight $(W, \mathrm{~g})$ & 0.077 \\
Catalyst density $\left(\rho_{s}, \mathrm{~kg} / \mathrm{m}^{3}\right)$ & 1980 \\
Mean pores radius $\left(r_{m p}, \mathrm{~m}\right)$ & $14 \times 10^{-9}$ \\
Particle radius $\left(r_{p}, \mathrm{~m}\right)$ & $0.15 \times 10^{-6}$ \\
Porosity of catalyst particle $\left(\varepsilon_{s}\right)$ & 0.69 \\
Tortuosity factor $\left(\tau_{s}\right)$ & 2.5 \\
Reactor length $(L, \mathrm{~m})$ & 0.3 \\
Reactor diameter $(D, \mathrm{~m})$ & 0.008 \\
Pd-Membrane properties: & \\
Membrane thickness $(\delta, \mathrm{m})$ & $20 \times 10^{-6}$ \\
Apparent activation energy $\left(\Delta E_{p}, \mathrm{~kJ} / \mathrm{mol}^{-6}\right)$ & 29.73 \\
Pre-exponential factor $\left(Q_{o}, \mathrm{~mol} . \mathrm{m} /\left(\mathrm{s} . \mathrm{m}^{2} . \mathrm{kPa}^{0.5}\right)\right.$ & $7.7 \times 10^{-5}$ \\
\hline
\end{tabular}

The Equation (23) must satisfy the following that:

$$
\int_{0}^{\tau_{1}} \widetilde{F}_{\mathrm{H}_{2} \mathrm{O}} \sigma_{1} f(t) d t=0
$$

Moreover, at $\mathrm{t}=0$

$$
F_{\mathrm{H}_{2} \mathrm{O}}(0)=\widetilde{F}_{\mathrm{H}_{2} \mathrm{O}}
$$

Then,

$$
\left(\frac{S}{C}\right)(t)=\left(\frac{S}{C}\right)\left(1+\sigma_{1} f(t)\right)
$$

The Equation (21) can be rewritten as follows:

$$
\widetilde{F}_{T}(t)=F_{\mathrm{CH}_{3} \mathrm{OH}}^{0}\left(1+\left(\frac{S}{C}\right)\left(1+\sigma_{1} f(t)\right)+2 X_{\mathrm{CH}_{3} \mathrm{OH}}-Y_{\mathrm{H}_{2}}+\frac{F_{\mathrm{H}_{2}}^{0}}{F_{\mathrm{CH}_{3} \mathrm{OH}}^{0}}\right)
$$

The function $f(t)$ can be a sinusoidal $f_{1}(t)$ or a square function $f_{2}(t)$ as defined according to Equations (1) and (2). The $\sigma_{1}$ is the running amplitude. The partial pressures of individual

\begin{tabular}{|c|c|c|}
\hline \multicolumn{3}{|l|}{ Kinetics Parameters } \\
\hline$C_{S 1}^{T}=7.5 \times 10^{-6} \mathrm{~mol} / \mathrm{m}^{2}$ & \multicolumn{2}{|c|}{$E_{R}=102.8 \mathrm{~kJ} / \mathrm{mol}$} \\
\hline$C^{T}{ }_{S 2}=7.5 \times 10^{-6} \mathrm{~mol} / \mathrm{m}^{2}$ & \multicolumn{2}{|c|}{$E_{W}=87.60 \mathrm{~kJ} / \mathrm{mol}$} \\
\hline$C_{S 2}^{T}=1.5 \times 10^{-5} \mathrm{~mol} / \mathrm{m}^{2}$ & \multicolumn{2}{|c|}{$E_{D}=170.0 \mathrm{~kJ} / \mathrm{mol}$} \\
\hline \multicolumn{3}{|l|}{$C_{S 2 a}^{T}=1.5 \times 10^{-5} \mathrm{~mol} / \mathrm{m}^{2}$} \\
\hline$S_{c}=50 \mathrm{~m}^{2} / \mathrm{g}$ & \multicolumn{2}{|c|}{$K_{0 R}=1.15 \times 10^{4} \mathrm{~atm}^{2}$} \\
\hline$k_{0 R}=9555 \mathrm{~m}^{2} / \mathrm{mol} . \mathrm{s}$ & \multicolumn{2}{|c|}{$K_{o W}=149.9 \mathrm{~atm}^{0}$} \\
\hline$k_{0 W}=31038 \mathrm{~m}^{2} / \mathrm{mol} . \mathrm{s}$ & \multicolumn{2}{|c|}{$K_{o D}=76.3 \mathrm{~atm}^{2}$} \\
\hline \multicolumn{3}{|l|}{$k_{O D}=373.8 \mathrm{~m}^{2} / \mathrm{mol} . \mathrm{s}$} \\
\hline \multicolumn{3}{|l|}{$\Delta H_{R}=48950 \mathrm{~J} / \mathrm{mol}$} \\
\hline \multicolumn{3}{|l|}{$\Delta H_{W}=-41180 \mathrm{~J} / \mathrm{mol}$} \\
\hline \multicolumn{3}{|l|}{$\Delta H_{D}=90130 \mathrm{~J} / \mathrm{mol}$} \\
\hline Parameters & $\Delta S_{i}(\mathrm{~J} / \mathrm{mol} . \mathrm{K})$ & $\Delta H_{i}(\mathrm{~kJ} / \mathrm{mol})$ \\
\hline$K_{\mathrm{CH} 3 \mathrm{OH}(l)}^{*}\left(\mathrm{bar}^{-0.5}\right)$ & -41.8 & -20 \\
\hline$K_{H C O O(l)}^{*}\left(\mathrm{bar}^{-1.5}\right)$ & 197.2 & 100 \\
\hline$K_{\mathrm{OH}(l)}^{*}\left(\mathrm{bar}^{-0.5}\right)$ & -44.5 & -20 \\
\hline$K_{H 2(a)}^{*}\left(\mathrm{bar}^{-1}\right)$ & -100.8 & -50 \\
\hline$K_{\mathrm{CH} 3 \mathrm{OH}(2)}^{*}\left(\mathrm{bar}^{-0.5}\right)$ & 30 & -20 \\
\hline$K_{O H(2)}^{*}\left(\mathrm{bar}^{-0.5}\right)$ & 30 & -20 \\
\hline
\end{tabular}
species (i) used in the rate expressions were evaluated as follows:

$$
P_{i}=P_{r} \frac{F_{i}(t)}{F_{T}(t)}
$$

with $P_{r}$ (bar) is the total pressure in the reactor and $F_{i}$ is the molar flow of species $i$. The axial

Table 2. Kinetic and thermodynamic parameters for methanol reforming on $\mathrm{Cu} / \mathrm{ZnO} / \mathrm{Al}_{2} \mathrm{O}_{3}$ 
differential mass balance in the gaseous phase is given for each component by:

$$
\frac{d F_{i}}{d L}=\rho A \sum_{j=1}^{3} \eta_{j} v_{i j} r_{i}
$$

where $A$ is the reactor section $\left(\mathrm{m}^{2}\right) ; v_{i j}$ is the stoichiometric coefficient of component $i$ in reaction $j ; r_{i}$ is the rate of the consumption or the formation of each species, given by:

$$
\begin{aligned}
& r_{\mathrm{CH}_{3} \mathrm{OH}}=-\eta_{1} r_{1}-\eta_{3} r_{3} \\
& r_{\mathrm{H}_{2} \mathrm{O}}=-\eta_{1} r_{1}-\eta_{2} r_{2} \\
& r_{\mathrm{CO}_{2}}=+\eta_{1} r_{1}+\eta_{2} r_{2} \\
& r_{\mathrm{CO}}=-\eta_{2} r_{2}+\eta_{3} r_{3} \\
& r_{\mathrm{H}_{2}}=+3 \eta_{1} r_{1}+\eta_{2} r_{2}+2 \eta_{3} r_{3}
\end{aligned}
$$

The effectiveness factor $\eta_{j}$ of each reaction is defined as the ratio of the observed reaction to the reaction rate calculated at external catalytic surface conditions. These factors are evaluated by the following expression [27]:

$$
\eta_{j}=\frac{\int_{0}^{V} r_{j}\left(P_{s, i}\right) \rho_{s}\left(\frac{d V}{V}\right)}{r_{j}\left(P_{i}^{r}\right) \rho_{s}}
$$

$\rho_{s}$ is the catalyst density $\left(\mathrm{kg} / \mathrm{m}^{3}\right)$. The mass balance for $\mathrm{CH}_{3} \mathrm{OH}, \mathrm{H}_{2} \mathrm{O}$, and $\mathrm{CO}_{2}$ is given by the following dimensionless equations ( $Z$ which is the dimensionless reactor length):

$$
\begin{aligned}
& \frac{d X_{\mathrm{CH}_{3} \mathrm{OH}}}{d Z}=\frac{\rho L A}{F_{\mathrm{CH}}^{0} \mathrm{OH}}\left(+\eta_{1} r_{1}+\eta_{3} r_{3}\right) \\
& \frac{d X_{\mathrm{H}_{2} \mathrm{O}}}{d Z}=\frac{\rho L A}{F_{\mathrm{CH}_{3} \mathrm{OH}}^{0}}\left(\eta_{1} r_{1}+\eta_{2} r_{2}\right) \\
& \frac{d X_{\mathrm{CO}_{2}}}{d Z}=\frac{\rho L A}{F_{\mathrm{CH}_{3} \mathrm{OH}}^{0}}\left(-\eta_{1} r_{1}-\eta_{2} r_{2}\right)
\end{aligned}
$$

Reaction and diffusion in a single symmetrical and isotropic catalyst pellet are described by the following equations:

$$
\nabla N_{i}=\sum_{j=1}^{3} v_{i, j} r_{s, j}
$$

$N_{i}$ is the flux of the species $i$

$$
N_{i}=-\frac{D_{e, i}}{R T} \frac{d P_{i}}{d r}
$$

The internal mass transfer resistances are accounted using the following expression.

$$
D_{e, i} \frac{d_{P_{s, i}}^{2}}{d \xi^{2}}=\rho_{s} R \operatorname{Tr}_{P}^{2} \sum_{j=1}^{3}\left(v_{i j} r_{s, j}\right)
$$

Then the mass balance in the catalytic solid is given for each component $\left(\mathrm{CH}_{3} \mathrm{OH}, \mathrm{H}_{2} \mathrm{O}, \mathrm{CO}_{2}\right.$, $\mathrm{CO}$, and $\mathrm{H}_{2}$, respectively) by the following expressions:

$$
\begin{aligned}
& D_{e, \mathrm{CH} \text { OH }} \frac{d_{P_{s, \mathrm{CH}} \mathrm{OH}}^{2}}{d \xi^{2}}+\rho_{s} R \operatorname{Tr}_{P}^{2}\left(-r_{1}-r_{3}\right)=0 \\
& D_{e, \mathrm{H}_{2} \mathrm{O}} \frac{d_{P_{s, H_{2} O} \mathrm{O}}^{2}}{d \xi^{2}}+\rho_{s} R \operatorname{Tr}_{P}^{2}\left(-r_{1}-r_{2}\right)=0 \\
& D_{e, \mathrm{CO} 2} \frac{d_{P_{s, \mathrm{CO} 2}}^{2}}{d \xi^{2}}+\rho_{s} R \operatorname{Tr}_{P}^{2}\left(+r_{1}+r_{2}\right)=0 \\
& D_{e, \mathrm{CO}} \frac{d_{P_{s, \mathrm{CO}}}^{2}}{d \xi^{2}}+\rho_{s} R \operatorname{Tr}_{P}^{2}\left(+r_{3}-r_{2}\right)=0 \\
& D_{e, \mathrm{H}_{2}} \frac{d_{P_{s, H_{2}}}^{2}}{d \xi^{2}}+\rho_{s} R \operatorname{Tr}_{P}^{2}\left(+3 r_{1}+r_{2}+2 r_{3}\right)=0
\end{aligned}
$$

Where, $\xi$ is the dimensionless pellet coordinate. The partial pressures of species $\mathrm{H}_{2} \mathrm{O}, \mathrm{H}_{2}$, and $\mathrm{CO}$ are related to the pressure of $\mathrm{CH}_{3} \mathrm{OH}$ by the following relations:

$$
\begin{aligned}
& D_{e, \mathrm{H}_{2} \mathrm{O}} \frac{d^{2} P_{s, \mathrm{H}_{2} \mathrm{O}}}{d \xi^{2}}=D_{e, \mathrm{CH} \mathrm{H}_{3} \mathrm{OH}} \frac{d^{2} P_{s, \mathrm{CH}} \mathrm{OH}}{d \xi^{2}}-D_{e, \mathrm{CO}} \frac{d^{2} P_{s, \mathrm{CO}}}{d \xi^{2}} \\
& D_{e, \mathrm{CO}} \frac{d^{2} P_{s, \mathrm{CO}}}{d \xi^{2}}=-D_{e, \mathrm{H}_{2}} \frac{d^{2} P_{s, \mathrm{H}_{2}}}{d \xi^{2}}-3 D_{e, \mathrm{CH} \text { OH }} \frac{d^{2} P_{s, \mathrm{CH}} \mathrm{OH}}{d \xi^{2}} \\
& D_{e, \mathrm{H}_{2}} \frac{d^{2} P_{s, \mathrm{H}_{2}}}{d \xi^{2}}=-D_{e, \mathrm{H}_{2} \mathrm{O}} \frac{d^{2} P_{s, \mathrm{H}_{2} \mathrm{O}}}{d \xi^{2}}-2 D_{e, \mathrm{CH} \mathrm{OHH}_{3}} \frac{d^{2} P_{s, \mathrm{CH}} \mathrm{OH}}{d \xi^{2}}
\end{aligned}
$$

Where, $P_{s, H 2 O}, P_{s, C O}$, and $P_{s, H 2}$ are evaluated by integration the Equations (47), (48), and (49), with the boundary conditions:

$$
\frac{d_{P_{s, \mathrm{CH}} \mathrm{OH}}^{2}}{d \xi^{2}}=\frac{d_{P_{s, \mathrm{CO}}}^{2}}{d \xi^{2}}=\frac{d_{P_{s, H_{2} O}}^{2}}{d \xi^{2}}=0 \text {, at } \xi=0
$$

$P_{s, \mathrm{CH} 3 \mathrm{OH}}=P_{\mathrm{CH} 3 \mathrm{OH}}, P_{s, \mathrm{CO} 2}=P_{\mathrm{CO} 2}, P_{s, \mathrm{H} 2 \mathrm{O}}=P_{\mathrm{H} 2 \mathrm{O}}$ at $\xi=1$

In general, in the solid phase continuity equation, the effective diffusivity of components $i$ is related to the molecular and Knudsen diffusivities [28]. Since the process operated under forcing conditions and in highly tur- 
bulent flow, the contribution of molecular diffusion is usually negligible [29]. Thus, using the average value of Knudsen diffusivity, the effective diffusivity would have the following form [27,30]:

$$
D_{e, i}=\frac{4 \varepsilon_{s}}{3 \tau_{s}} \frac{r_{m p}}{2} \sqrt{\frac{8 R T}{\pi M_{i}}}
$$

$r_{m p}$ is mean pores radius (m), $T$ is temperature (K), $R$ is universal gas constant $(8.314 \mathrm{~J} / \mathrm{mol} \mathrm{K})$, $\tau_{s}$ is tortuosity factor, $\varepsilon_{s}$ is porosity of catalyst particle, and $M_{i}$ is the molar mass $(\mathrm{kg} / \mathrm{mol})$.

\section{b) In permeate side:}

The permeate hydrogen flow rate at any distance in the membrane having a radius $r_{m}(m)$ is written as follows:

$$
\frac{d F_{H_{2, p}}}{d L}=2 \pi r_{m} J_{H_{2}}
$$

The flux of hydrogen permeating through the $\mathrm{Pd}$ membrane with a thickness $\delta$ is assumed to follow the half-power pressure law [31] and is expressed by:

$$
J_{H_{2}}=\frac{Q}{\delta}\left(P_{H_{2, r}}^{0.5}-P_{H_{2, p}}^{0.5}\right)
$$

The hydrogen permeation coefficient $Q$ is a strong function of temperature and can be described by an Arrhenius type of equation, as follows:

$$
Q=Q_{0} \exp \left(-\Delta E_{p} / R T\right)
$$

The hydrogen permeation activation energy and the pre-exponential factor are taken from Basile et al. [32]. In this relation, $\Delta E_{p}$ is hydrogen permeation activation energy, $\mathrm{kJ} / \mathrm{mol} ; \mathrm{Q}$ is is the permeation coefficient of hydrogen, $\mathrm{mol} / \mathrm{m} \mathrm{s} \mathrm{Pa}^{0.5} ; Q_{o}$ is is pre-exponential factor, $\mathrm{mol} / \mathrm{m} \mathrm{s} \mathrm{Pa}^{0.5}$.

On the other hand, we have:

$$
F_{\mathrm{H}_{2, p}}=Y_{\mathrm{H}_{2}} F_{\mathrm{CH}_{3} \mathrm{OH}}^{0}
$$

Substituting $J_{H 2}, Q$, and $F_{H 2, p}$ are given by Eqs. (54), (55), and (56) in eq. (53) and by introducing a dimensionless length, we obtain:

$$
\frac{d Y_{H_{2}}}{d Z}=\frac{2 \pi r_{m} L}{\delta F_{C H_{3} \mathrm{OH}}^{0}} Q_{0} \exp \left(-\Delta E_{p} / R T\right)\left(P_{H_{2, r}}^{0.5}-P_{H_{2, p}}^{0.5}\right)
$$

$P_{H 2, r}$ is the hydrogen partial pressure in the reaction side. The hydrogen pressure in the permeate zone $P_{H 2, p}$ is defined by:

$$
P_{H_{2, p}}=\frac{Y_{H_{2}} P_{P}}{Y_{H_{2}}+I}
$$

$I$ is the sweeping gas to methanol ratio, which is defined as the ratio of the sweeping gas flow rate $\left(F_{I}^{o}\right)$ to that of methanol at the inlet of the catalyst bed $\left(\mathrm{F}_{\mathrm{CH}}^{\mathrm{COH}}\right)$.

$$
I=\frac{F_{I}^{0}}{F_{\mathrm{CH}_{3} \mathrm{OH}}^{0}}
$$

Under forcing conditions using a periodic function $f(t)$, we obtain:

$$
\begin{aligned}
& I=\frac{F_{I}(t)}{F_{C H_{3} \mathrm{OH}}^{0}}=\frac{\widetilde{F}_{I}+\widetilde{F}_{I} \sigma_{2} f(t)}{F_{\mathrm{CH}_{3} \mathrm{OH}}^{0}} \\
& F_{I}(t)=\widetilde{F}_{I}+\widetilde{F}_{I} \sigma_{2} f(t)
\end{aligned}
$$

The equation (61) must satisfy the conditions that:

$$
\begin{aligned}
& \int_{0}^{\tau_{2}} \widetilde{F}_{I} \sigma_{2} f(t) d t=0 \\
& F_{I}(0)=\widetilde{F}_{I}
\end{aligned}
$$

The function $f(t)$ can be a sinusoidal $f_{l}(t)$ or a square function $f_{2}(t)$ as defined above according to Equations (1) and (2) and $\sigma_{2}$ is the running amplitude.

\section{Results and Discussion}

\subsection{Solution procedure}

The principal running modes of steam to methanol ratio $(\mathrm{S} / \mathrm{C})$ and of sweep gas ratio $(I)$ are presented in Figure 2. The established differential equations for the gas phase on reaction and permeate sides are integrated by Runge-Kutta method [33]. Once the partial pressures for all the components $\left(P_{s, i}\right)$ are obtained, the effectiveness factors for the considered reactions are calculated by the orthogonal collocation method [33]. The characteristics equations of the periodic operations are considered. Here, the steam to methanol and sweeping gas to methanol ratios are oscillated around their steady state values which are 1 and 3 , respectively. In order to evaluate the potential of periodic reactor operation by means of mathematical modeling, methanol conversion and hydrogen recovery are used as indicators to quantify the process performances. Let us assume that, when the reaction was performed under steady state operation, $\widetilde{X}_{\mathrm{CH}_{3} \mathrm{OH}}$

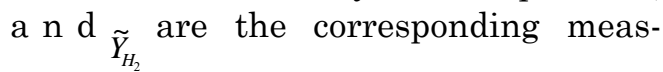


urements of methanol conversion and of hydrogen recovery, respectively. Their average values under unsteady state conditions are $X_{\mathrm{CH} 3 \mathrm{OH}}$ and $Y_{H 2}$, respectively.

$$
\begin{aligned}
& \Delta X=X_{\mathrm{CH}_{3} \mathrm{OH}}-\widetilde{X}_{\mathrm{CH}_{3} \mathrm{OH}} \\
& \Delta Y=Y_{\mathrm{H}_{2}}-\widetilde{Y}_{\mathrm{H}_{2}}
\end{aligned}
$$

The differences of $\Delta X$ and $\Delta Y$ could be negative, zero or positive. If $\Delta X$ and $\Delta Y$ are positives, the periodic operation can be considered as favorable, as they correspond to increased conversion and hydrogen recovery, in comparison to the steady state operation.

\subsection{Discussion}

The purpose of the simulation is aimed to study the effect of the modulation of inlet feed composition and sweeping gas (inputs) on proc-
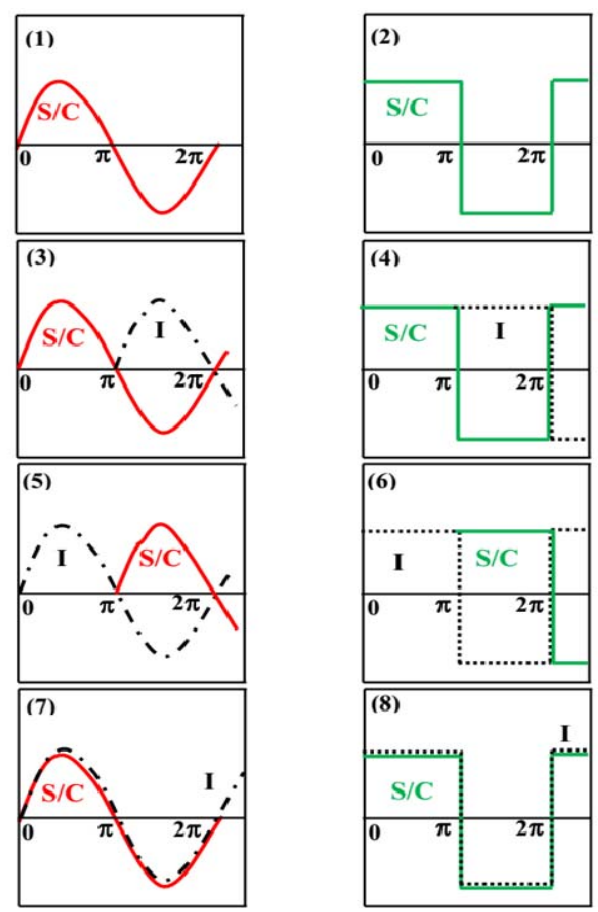

Figure 2. The principal running modes of inputs parameters: (1) Modulation of S/C by sinusoidal way at I constant, (2) Modulation of $\mathrm{S} / \mathrm{C}$ by square way at I constant, (3) Modulation of S/C and I by sinusoidal way; $\mathrm{I}$ is out of phase (phase lag $=\pi$ ), (4) Modulation of $\mathrm{S} / \mathrm{C}$ and I by square way; I is out of phase (phase lag= $\pi$ ), (5) Modulation of I and S/C by sinusoidal way; S/C is out of phase (phase lag $=\pi$ ), (6) Modulation of I and $\mathrm{S} / \mathrm{C}$ by square way; $\mathrm{S} / \mathrm{C}$ is out of phase (phase lag $=\pi$ ), (7) Modulation of S/C and I in phase by sinusoidal way, (8) Modulation of S/C and I in phase by square way ess performance. To evaluate the reactor behavior and its performance during cyclic operation, all calculations were carried out at $533 \mathrm{~K}$ and at total reaction pressure of 1.4 bar. These performances were quantified by the criterions metrics ( $\Delta X$ and $\Delta Y$ ) defined above and only the significant results are shown below for an amplitude range between 0 and 0.3 . Performance comparison was considered for two cases of interest: steady state operation (represented by horizontal lines) and periodic operation.

\subsubsection{Modulation of steam to methanol ratio} (S/C) at constant sweeping gas to methanol ratio (I)

Figure 3 shows the evolution of methanol conversion and hydrogen recovery with modulation of steam to methanol ratio $(S / C)$ at constant sweeping gas to methanol ratio $(I)$. The inputs modulation was performed via a square wave function and a sinusoidal function. The main results show that the first run using a square function allowed the highest conversion; the second one which is running with a sinusoidal function shows lower methanol conversion. Here, it appears that the effect of modulation of $S / C$ ratio was powerful and dominant; the methanol conversion was boosted above the steady state levels for both variants of modulation. Therefore the hydrogen recovery was also increased over the steady state level when the running amplitude is ranged from 0.025 to 0.25 in the case of the square function wave. In the case of the sinusoidal function, the hydrogen recovery can be also enhanced when using the amplitude range

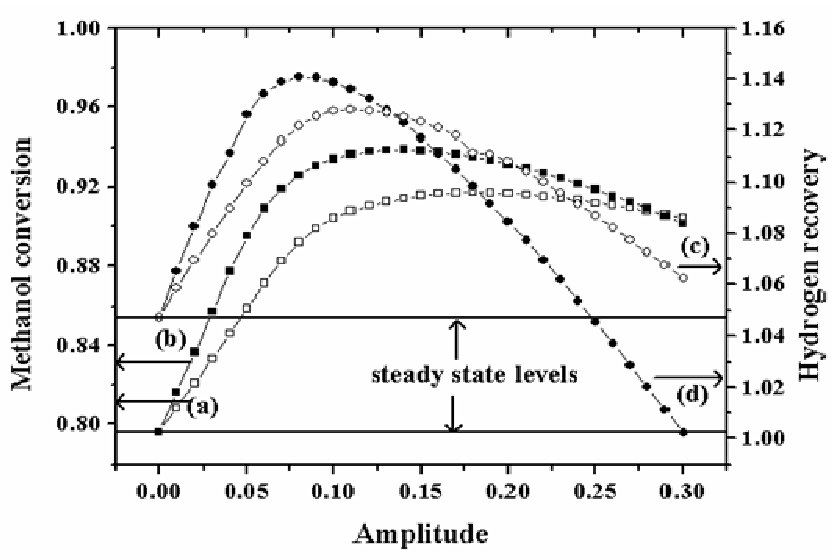

Figure 3. Reactor response for modulation of $\mathrm{S} / \mathrm{C}$ at I constant. (a) and (b): methanol conversion by sinusoidal and square way, respectively (c) and (d):hydrogen recovery by sinusoidal and square way, respectively 
from 0.025 to 0.3 . It should be noted that, the improvement in performances can be obtained when the criterions metrics $\Delta X$ and $\Delta Y$ are positives. In the case of modulation by a square function, it was observed a non-enhancement zone when the amplitude was between 0.25 and 0.30 . The absence of this zone in the case of sinusoidal modulation was observed.

A notable difference in the criterions metrics was obtained for the two modes of modulation. The optimal amplitudes giving the best (higher) performance are as follows: In the case of the sine modulation, the obtained highest conversion was $91 \%$ corresponding to the optimal amplitude of 0.18 ; the optimum quantity of hydrogen recovered was 1.12 which corresponds to the optimal amplitude of 0.12 . The optimal amplitudes that give the best performances in the case of square wave are as follows: for the conversion, an amplitude of 0.14 can boost the conversion to $94 \%$, on the other hand an amount of the hydrogen of 1.14 can be recovered at low amplitude (0.08). Based on these results, it is clear that the effect of modulation of steam to methanol ratio is a favorable way which can be used for obtaining performance above the steady state. i.e. switching the inlet composition $(S / C)$ around the steady state value between low and high values can boost the conversion and hydrogen yield. This can be explained by the fact that under the using forcing conditions, the methanol steam reforming reaction was enhanced in the direction of hydrogen production. In other hand, performing the system under periodic operation for the running amplitudes by means of a symmetric square way is more favorable compared to the sine mode, because it is the most effective and it guarantees the largest possible variation from the mean value.

\subsubsection{Modulation of steam to methanol ratio} $(S / C)$ in phase and sweeping gas to methanol ratio $(I)$ out of phase

To examine the effect of steam to methanol and sweeping gas to methanol ratios on the reactor performance with another variant of modulation, these inputs were modulated as follows: the steam to methanol ratio $(S / C)$ was in phase and the sweeping gas ratio $(I)$ was running out of phase (phase lag $=\pi$ ). Figure 4 shows the methanol conversion and the hydrogen recovery as function the amplitude for the two modes of modulation. The main results show that there was a significant improvement in conversion compared to the steady state conditions for both cases of modulation (sinusoidal and square). The quantity $\Delta X$ was positive all over the range of the considered amplitudes. On the other hand, because the quantity $\Delta X$ was still higher than that of the sine mode, it is noteworthy that the use of square signal gives good results in terms of conversion. The higher value of the criterion $\Delta X$ was 0.14 which is obtained at an amplitude of 0.14 in the case of modulation by a square function. While for the sine modulation, the higher value of the quantity $\Delta X$ was 0.12 which is obtained for an amplitude of 0.18 .

Regarding the hydrogen recovery, it should be noted that there was a slight improvement in a very small amplitude range for both modulation modes. When the modulation was performed by a square function, the results show that from the amplitude of 0.018 , the criterion $\Delta Y$ becomes less than or equal to zero. In the case of the sinusoidal function, the corresponding amplitude in which this quantity is less than or equal to zero was 0.125 . It should be noted that beyond these amplitude values, there was no performance improvement. This reactor response can be explained by the fact that the phase lag between the modulated inputs, i.e. the steam to methanol and sweeping gas ratios operate alternately. During the S/C was modulated with the wave which goes from low to high amplitudes (above the steady state level); there was an enhancement of the methanol conversion, because methanol and steam becomes in excess, which favors the methanol steam reforming reaction. For the case when the wave goes from high to low values amplitudes (below the steady state level), there was a decrease in methanol conversion and in par-

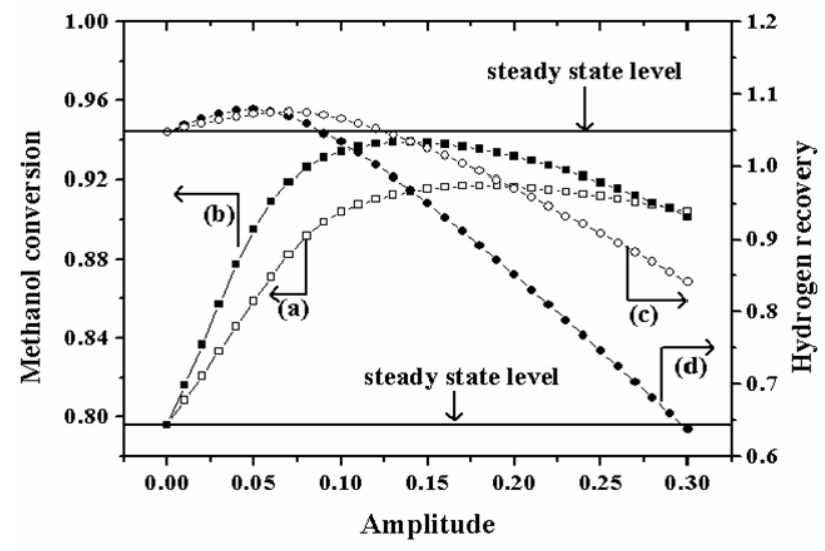

Figure 4. Reactor response for modulation of $\mathrm{S} / \mathrm{C}$ and I out of phase (phase $\mathrm{lag}=\pi$ ), (a) and (b): methanol conversion by sinusoidal and square way, respectively, (c) and (d): hydrogen recovery by sinusoidal and square way, respectively 
allel the modulation of sweeping gas ratio is started in the positive direction by removing hydrogen present in permeate side. Here, the hydrogen pumping through the membrane was not occurred and the reverse water gas shift reaction is favored for consuming hydrogen. Based on these results it should be noted that this condition of modulation is not favorable for obtaining best performances, especially in terms of pure hydrogen recovery.

\subsubsection{Modulation of sweeping gas to methanol} ratio $(I)$ in phase and steam to methanol ratio $(S / C)$ out of phase

Figure 5 shows the reactor response when the sweeping gas to methanol $(I)$ is in phase and the steam to methanol $(S / C)$ ratio is running out of phase (here the phase lag is equal to $\pi)$. Clearly, under this variant of modulation, the periodic operation offered much lower conversion and hydrogen yield than steady state operation. No enhancement of methanol conversion and hydrogen recovery was measured for the sine or square function. Since the quantities $\Delta X$ and $\Delta Y$ are negative, this mode of modulation with sine and square functions was not favorable to obtain the best performance. This could be explained by the fact that a large amount of hydrogen produced was consumed via the reverse water gas shift reaction. i.e. when starting the modulation of sweeping gas, initially the permeate side is poor in hydrogen because the modulation of $S / C$ was not yet started (here the $S / C$ and $I$ ratios are not in phase).

On the other hand, when the modulation of $S / C$ was started, the methanol conversion was

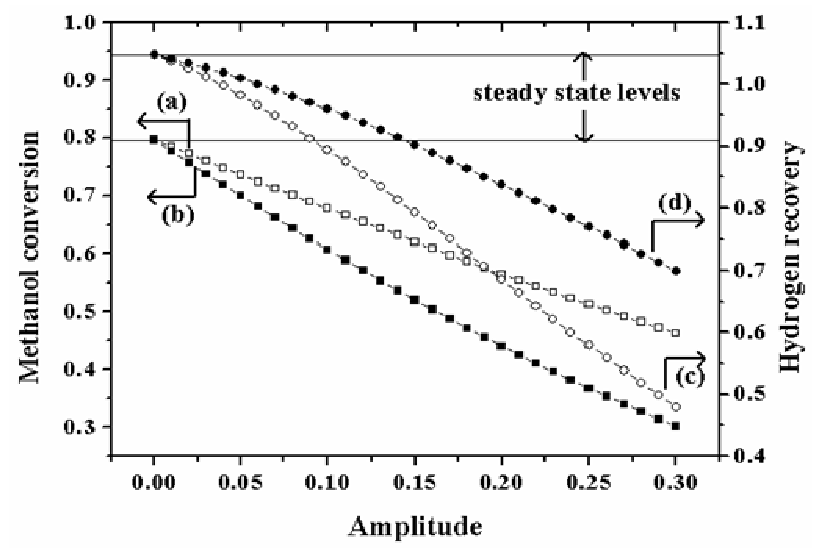

Figure 5. Reactor response for modulation of I and $\mathrm{S} / \mathrm{C}$ out of phase (phase lag $=\pi$ ), (a) and (b): methanol conversion by sinusoidal and square way, respectively, (c) and (d):hydrogen recovery by sinusoidal and square way, respectively improved, at this moment the modulation of sweeping gas was not yet started, so the amount of hydrogen which is normally removed by the sweeping gas reacts according to reverse water gas shift reaction. This can be further explained by the incoherence actions between the two inputs used under this variant of modulation.

\subsubsection{Modulation of steam to methanol ratio} $(\mathrm{S} / \mathrm{C})$ and sweeping gas to methanol ratio $(I)$ both in phase

The study of the effect of modulation of steam to methanol $(S / C)$ and sweeping gas to methanol ( $I$ ) ratios running both in phase show a positive behavior. This behavior can be explained by means of Figure 6, in which the conversion and hydrogen recovery levels for both runs are presented. Since the measurements $\Delta X$ and $\Delta Y$ are positives, high methanol conversion and pure hydrogen can be obtained using the sine and square functions for modulation of the considered inputs. It is noteworthy that the obtained results concerning the hydrogen yields and methanol conversion in the case of modulation via a square function are greater than the obtained in the case of modulation by sinusoidal function.

The hydrogen permeation was affected by the periodic operation. The hydrogen removal to permeate side decreases the hydrogen pressure in reaction side, and thus drives the methanol reforming toward the products of methanol steam reforming reaction, resulting in more methanol conversion. Considering the obtained hydrogen yield (Figure 6), it was found that the periodic operation provided hy-

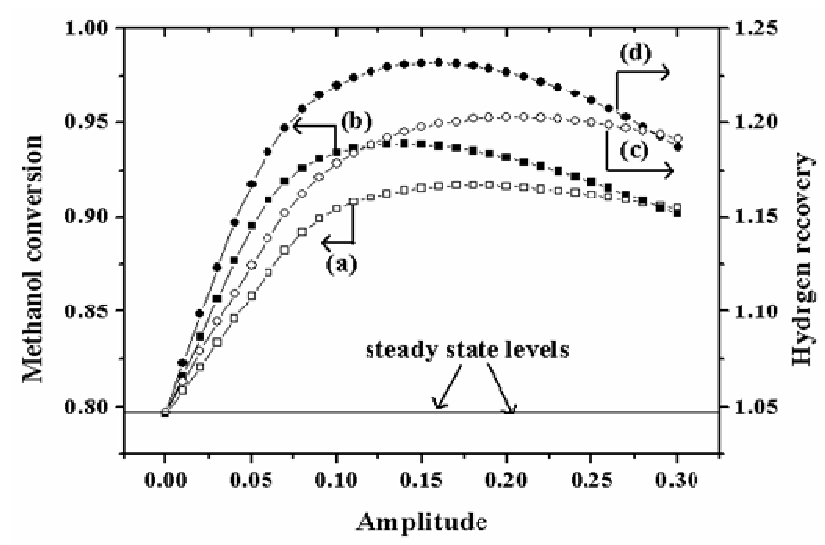

Figure 6. Reactor response for modulation of $\mathrm{S} / \mathrm{C}$ and I in phase. (a) and (b): methanol conversion by sinusoidal and square way, respectively, (c) and (d): hydrogen recovery by sinusoidal and square way, respectively 
drogen yield as high as that of the steady state operation, indicating equivalent performance of periodic operation at $533 \mathrm{~K}$. Based on these results, the applied mode of periodic operation seemed to become an attractive operation mode regarding the equivalent hydrogen yield. It should be noted that there was an optimal amplitude for obtaining best performances. For example, once the process was performed with the square wave function, the optimal amplitudes give the following performances: for methanol conversion the optimal amplitude was 0.14 giving a $\Delta X=0.14$, while the $\Delta Y=0.18$ was obtained with an optimal amplitude of 0.16 .

When the reactor was operated under periodic operation according to the sinusoidal function, the optimal amplitude (0.18) gives a $\Delta X=0.12$, and the optimal amplitude concerning the sweeping gas (0.20) gives a $\Delta Y=0.15$. Therefore, it was obtained that tuning the inlet composition feed and the sweeping gas with square wave function can boost the reactor performance compared to the sinusoidal periodic operation. Here, it is clear that the coherence and the harmony between modulation of $S / C$ and $I$ running both in phase, can boost significantly the reactor performance above the steady state level. i.e. the modulation of steam to methanol ratio enhance the methanol conversion, at the same time, the modulation of sweeping gas enhance the hydrogen recovery by shifting the equilibrium towards the direction of hydrogen production. In this case, the reverse water gas shift reaction could not be occurred. Consequently, the methanol conversion was still improved again.

\section{Conclusion}

In conclusion, we would like to emphasize once more the key role of the periodic operations. Periodic operation was applied for methanol steam reforming in a $\mathrm{Pd}$-membrane reactor. A comparative analysis of the different variants of modulation has demonstrated that modulating the $\mathrm{S} / \mathrm{C}$ and $\mathrm{I}$ ratios both in phase with a square wave function appears to be the best strategy to enhance the reactor performances. The best performances could be obtained if the inlet composition and the sweeping gas are tuned at optimal amplitudes of 0.14 and 0.16 , respectively. This method of reactor operation presents a new and strategic way for pure hydrogen production from methanol steam reforming. The hydrogen being produced in this intensified novel process could be directly used in fuel cells.

\section{Acknowledgements}

This work was supported in part by the University Ferhat Abbas Sétif 1, and the Ministry of Higher Education and Scientific Research (Algeria) with Project No. A16N01UN190120150009. Both are gratefully acknowledged.

\section{References}

[1] Cheng, W.H. (1999). Development of methanol decomposition catalysts for production of $\mathrm{H}_{2}$ and CO. Accounts of Chemical. Research, 32: 685-691.

[2] Yong, S.T., Hidajat, K., Kawi, S. (2004). Reaction study of autothermal steam reforming of methanol to hydrogen use a novel nano CuZnAl-catalyst. Journal of Power Sources, 131: 91-95.

[3] Ersoza, A., Olguna, H., Ozdogan, S., Gungora, C., Akguna, F., Tiris, M. (2003). Autothermal reforming as a hydrocarbon fuel processing option for PEM fuel cell. Journal of Power Sources,118: 384-392.

[4] Chin, Y.H., Robert, D., Hu, J., Alice, C.D., Wang, Y. (2002). Steam reforming of methanol over highly active $\mathrm{Pd} / \mathrm{ZnO}$ catalyst. $\mathrm{Ca}$ talysis Today, 77: 79-88.

[5] Kruger, P. (2001). Electric power requirement for large-scale production of hydrogen fuel for the world vehicle fleet. International Journal of Hydrogen Energy, 26: 1137-1147.

[6] Giunta, P., Mosquera, C., Amadeo, N., Labrode, M. (2007). Simulation of a hydrogen production and purification system for a PEM fuel cell using bioethanol as raw material. Journal of Power Sources, 164: 336-343.

[7] Hamelinck, C.N., Andre, P.C.F. (2002). Future prospects for production of methanol and hydrogen from biomass. Journal of Power Sources, 111: 1-22.

[8] Levin, D.B., Chahine, R. (2010). Challenges for renewable hydrogen production from biomass. International Journal of Hydrogen energy, 35: 4962-4969.

[9] Perna, A. (2007). Hydrogen from ethanol: Theoretical optimization of a PEMFC system integrated with a steam reforming processor. International Journal of Hydrogen energy, 32: 1811-1819.

[10] Brown, L.F. (2001). A comparative study of fuels for on-board hydrogen production for fuel-cell-powered automobiles. International Journal of Hydrogen Energy, 26: 381-397.

[11] Holladay, J.D., Wang, Y., Jones, E. 2004). Review of developments in portable hydrogen 
production using microreactor technology. Chemical Reviews, 104: 4767-4790.

[12] Harold, M.P., Nair, B., Kolios, G. (2003). Hydrogen generation in a $\mathrm{Pd}$ membrane fuel processor: assessment of methanol-based reaction systems. Chemical Engineering Science, 58: 2551-2571.

[13] Sun, J., Qiu, X.P., Wu, F., Zhu, W.T. (2005). $\mathrm{H}_{2}$ from steam reforming of ethanol at low temperature over $\mathrm{Ni} / \mathrm{Y}_{2} \mathrm{O}_{3}, \quad \mathrm{Ni} / \mathrm{La}_{2} \mathrm{O}_{3}$ and $\mathrm{Ni} / \mathrm{Al}_{2} \mathrm{O}_{3}$ catalysts for fuel-cell application. International Journal of Hydrogen Energy, 30: 437-445.

[14] Wang, G., Wang, F., Li, L., Zhang, G. (2013). A study of methanol steam reforming on distributed catalyst bed. International Journal of Hydrogen Energy, 38: 10788-10794.

[15] Mateos-Pedrero, C., Silva, H., PachecoTanaka, D.A., Liguori, S., Iulianelli, A., Basile, A., Mendes, A. (2015). CuO/ZnO catalysts for methanol steam reforming: The role of the support polarity ratio and surface area. Applied Catalysis B: Environmental, 174-175: 67-76.

[16] Gribovskiy, A.G., Makarshin, L.L., Andreev, D.V., Klenov, O.P., Parmon, V.N. (2015). Thermally autonomous microchannel reactor to produce hydrogen in steam reforming of methanol. Chemical Engineering Journal 273: 130-137.

[17] Holladay, J.D., Hu, J., King, D.L., Wang, Y. (2009). An overview of hydrogen production technologies. Catalysis Today, 139: 244-260.

[18] Armor, J.N. (1998). Applications of catalytic inorganic membrane reactors to refinery product. Journal of Membrane Science, 147: 217 233.

[19] Chibane, L., Djellouli, B. (2012). Role of periodic input composition and sweeping gas for improvement of hydrogen production in a palladium membrane reactor by partial oxidation of methane. Chinese Journal of Chemical Engineering, 20: 577-588.

[20] Aida, T., Silveston, P.L. (2005). Periodic operation in: "cyclic separating reactors". Blackwell publishing Ltd.

[21] Peppley, B.A., Amphlett, J.C., Kearns, L.M., Mann, R.F. (1999). Methanol-steam reforming on $\mathrm{Cu} / \mathrm{ZnO} / \mathrm{Al}_{2} \mathrm{O}_{3}$. Part 1 : the reaction network. Applied Catalysis A: General, 179: 2129.

[22] Peppley, B.A., Amphlett, J.C., Kearns, L.M., Mann, R.F. (1999). Applied Catalysis A: General, 179: 31-49.
[23] Asprey, S.P., Wojciechowski, B.W., Peppley, B.A. (1999). Kinetic studies using temperature-scanning: the steam-reforming of methanol. Applied Catalysis A: General, 179: 51-70.

[24] Agarwal, V., Patel, S., Pant, K.K. (2005). H production by steam reforming of methanol over $\mathrm{Cu} / \mathrm{ZnO} / \mathrm{Al}_{2} \mathrm{O}_{3}$ catalysts: transient deactivation kinetics modeling. Applied Catalysis A: General, 279: 155-164.

[25] Jiang, Y.L., Lim, M.S., Kim, D.H. (2001). Simulation studies of the hydrogen from methanol partial oxidation steam reforming by a tubular packed-bed reactor. Chinese Journal of Chemical Engineering, 9: 297-305.

[26] Israni, S.H., Harold, M.P. (2011). Methanol steam reforming in single-fiber packed bed Pd-Ag membrane reactor: Experiments and modeling. Journal of Membrane Science, 369: 375-387.

[27] Pedernera, M.N., Pina, J., Borio, D.O. (2007). Kinetic evaluation of carbon formation in a membrane reactor for methane reforming. Chemical Engineering Journal, 134: 138-144.

[28] Ji, P., van der Kooi, H.J., de Swaan Arnos, J. (2003). Simulation and thermodynamic analysis of conventional and oxygen permeable CPO reactors. Chemical Engineering Science, 58: 2921-2930.

[29] Froment, G.F., Bischoff, K.B. (1979). Chemical Reactor Analysis and Design, John Wiley $\&$ Sons Inc.

[30] Krishna, B., Nair, R., Harold, M.P. (2006). Hydrogen generation in a $\mathrm{Pd}$ membrane fuel processor: Productivity effects during methanol steam reforming. Chemical Engineering Science 61: 6616-6636.

[31] Tiemersma, T.P., Patil, C.S., van Sint Annaland, M., Kuipers, J.A.M. (2006). Modelling of packed bed membrane reactors for autothermal production of ultrapure hydrogen. Chemical Engineering Science, 61: 1602-1616.

[32] Basile, A., Paturzo, L., Lagana, F. (2001). The partial oxidation of methane to syngas in a palladium membrane reactor: simulation and experimental studies. Catalysis Today, 67: 65-75.

[33] Finlayson, B.A. (1980). Nonlinear Analysis in Chemical Engineering. McGraw-Hill New York. 